\title{
Coping Strategies of College Instructors' Professional Identity
}

\author{
Yuchuan LUO \\ Institute of Aviation Human Factors\& Ergonomics \\ Civil Aviation Flight University of China \\ Guanghan Sichuan China
}

\author{
Xuemei DENG ${ }^{*}$ \\ Department of Cabin Crew \\ Civil Aviation Flight University of China \\ Guanghan Sichuan China
}

\begin{abstract}
High professional identity is an important prerequisite for the development of the work of instructors, and is an important guarantee for the validity of the work. To study the coping strategies of college instructors' professional identity, this paper analyzes the reasons lead to low professional identity of college instructors. Due to the mismatch between occupational stress and social support system, instructors' occupation requirements and occupation ability, job content and career achievement led to the phenomenon of college instructors' professional identity is low. To improve the professional identity of college instructors by providing more training opportunities, job funding and career development opportunities, establishing the self-coping system and improving the evaluation system. The originality of this paper is to analyze the reasons for the low professional identity of college instructors and put forward coping strategies.
\end{abstract}

Keywords - college instructors; professional identity; coping strategies; belonging; happiness; fulfillment

\section{INTRODUCTION}

The professional identity of college instructors refers to the positive evaluation of their career, which is the state and process of self-adjustment of occupational adaptation and development [1]. College instructors not only engage in the teaching work of some colleges and universities, but also undertake the ideological and political education work. They have the dual identity of "double qualified teachers", which plays an extremely important role in the cultivation of college students and the stability of the college campus. The professional identity of college instructors will directly affect the job satisfaction, work responsibility and effectiveness of the instructors; influence the development of college instructors; and even affect the ideological and political work and the development of education and teaching work. Therefore, analyze the status quo and causes and put forward coping strategies to enhance the professional identity of college instructors' professional identity have a very positive role.

\section{THE STATUS QUO OF PROFESSIONAL IDENTITY OF COLLEGE INSTRUCTORS}

College instructors have special professional characteristics [2]. In fact, instructors compared with full-time teachers, occupation uncertainty, lack of job attractiveness, leads to poor stability of post, most college instructors want to transfer to a

Science Foundation of Civil Aviation Administration of China (MHRD201129; 2006RKXZY17); Foundation project of Sichuan Provincial Education Department (study on psychological stress support program for civil aviation pilots) full-time teacher or administrative staff in Colleges, the instructors' occupation identity is generally low.

\section{ANALYSIS OF THE CAUSES OF COLLEGE INSTRUCTORS ' PROFESSIONAL IDENTITY}

\section{A. Occupational Stress does not match the Support System}

College instructors are the stable maintainer of college campus. With the advent of the Internet era, the ideological changes, many students showed the characteristics of rebellious, low frustration tolerance, poor interpersonal tension and safety consciousness, those conditions put forward new requirements for the works of instructors. Instructors are the frontline posts for students. Once emergency happens, instructors are required to arrive at the scene first and deal with the problems. Therefore, the general requirements of instructors on duty in the student dormitory in turns, and 24 hours of standby for mobile phone, which leads to a part of the instructors long-term in a state of emergency emotional tension and insomnia. This is one of the important reasons for College instructors occupational stress.

College instructors have great occupational stress, but lack of corresponding social support system, which is caused by the following reasons. First, the status of the college instructors is not recognized. College instructors lack of technical content, just manage the daily life of students, playing the role of "nanny". Second, the position of college instructors has not been recognized by family members. Because the work of instructors has the characteristic of unfixed long working hours, leading to instructors often lack of private time, leading to the imbalance of family role, those causing family members to their occupation extremely discontent and complaints. College instructors' professional stress and social support system does not match, instructors occupation status is low, which leads to instructors' psychological imbalance, lack of enthusiasm for work and job burnout.

\section{B. Professional Role Requirements does not match Professional Competence}

According to the "Standard of professional ability of Colleges instructors", college instructors are an important part of the teaching staff and management team in Colleges, they have dual identities of teachers and cadres. This definition clearly defines the professional role of instructors, not only has a certain professional quality, but also has a strong ability of 
political and ideological education. As far as the present situation of college instructors is concerned, it is still difficult to have these abilities. First, the structure, educational background and knowledge background of college instructors are uneven. Compared with full-time teachers, college instructors' entry threshold is low, bachelor degree majority but master and doctor are relatively few. Some college instructors are workers, veterans of professional school or transfer dispatch personnel, those staff professional knowledge and scientific research ability is low. From the subject background, the college instructors before entering the job is not with the management, psychology, education, sociology and other disciplines background knowledge. Second, the age of college instructors is low. The frequent replacement of instructors leads to the phenomenon of younger age. Most of the new instructors are newly employed college graduates. They have passion, but they are disadvantages in life experience, mental maturity and emotional management[3]. This makes them unable to become students' spiritual mentor and life guider. The mismatch between the professional role requirements and the professional ability of the instructors will lead to the frustration of college instructors' ability, and then lead to a lower sense of professional efficacy and sense of belonging.

\section{Work Content does not match Career Achievement}

The work content of college instructors involves all aspects of College Students. Those works involve a wide range, but the performance is difficult to quantify. First, the instructor repeats the mechanical work, spend a lot of time and effort, but the results are invisible and not significant. Instructors' work does not require high innovation, but its work without error requirements is very high. Therefore, the small errors in the work also easily lead to the denial of the whole work results, and then dispel the enthusiasm of instructors. At the same time, instructors' work is often reward averaging; it is difficult for instructors to form a good sense of professional accomplishment. Second, there is no direct relationship between job content and job title evaluation. Instructors can choose a series of teachers or a series of studies, but from the relevant requirements of professional titles, instructors are at a inferiority. Based on the above two reasons, the instructors' work content and career achievement does not match, so it is difficult for instructors to build self-confidence and identity from work.

\section{COPING STRATEGIES TO IMPROVE COLLEGE INSTRUCTORS’ PROFESSIONAL IDENTITY}

\section{A. Clear Career Development Plan to Improve the Sense of Belonging}

To enhance the professional identity of instructors, colleges should first increase the support for instructors' career development, in order to help instructors cope with the stress of work, and make the negative emotions in their work to be resolved. Colleges should provide more training support, job funding support and career prospect support for instructors. "Regulations on the Construction of College Instructors" mentioned: Colleges should positively select excellent instructors to participate in domestic and international exchanges, inspection and further study, and support instructors study relevant professional degree on the basis of ideological work. From this regulation, it is found that it's necessary to provide a channel for instructors to improve their academic qualifications and improve the professional level of instructors[4]. Therefore, colleges should provide professional training and further study opportunities for instructors, and provide planned characteristic training for instructors to help them build good and positive career expectations, and a career prospect of sustainable development, so as to improve their sense of belonging to their posts.

\section{B. Establish Self-response System to Improve Job Happiness}

To improve college instructors' professional identity, instructors also need to change their attitudes. College instructors should establish a positive self-response system, through the improvement of understanding, clear positioning. College instructors really accept the post of instructors, change the pressure into motivation, stimulate the enthusiasm of the work, and realize the self-worth in the post. The establishment of positive coping system mainly includes correct selfcognition, self-planning and management and self-adjustment. Instructors' correct self-cognition refers to the correct understanding of their ability level, knowledge structure, advantages and disadvantages, to find the combination of reality and ideal, to clear the work fitness, and correctly understand the relationship between work and self. Instructors' self-planning and management means that Instructors combine their own characteristics and job requirements develop a series of goals to meet the requirements of the post, and form internal power, so as to achieve the purpose of self-planning and management. Instructors' self-adjustment refers to the instructors to learn to establish positive coping strategies, learn to vent and manage emotions, good and healthy rest and diet measures. Through the establishment of positive self-response system, and constantly improve the instructors' identity to the job, it becomes the internal power of hard work[5].

\section{Improve the Evaluation System and Enhance the Sense of Achievement}

A good evaluation system is a scientific and effective means of Vocational encouragement, and an important way for instructors to gain their sense of achievement, and the impetus to promote the development and perfection of instructors. First of all, due to the hidden tasks in the work of instructors, the existing evaluation system[6] is difficult to move completely competent. From the nature and characteristics of instructors' work, the work can be divided into three sections: Students' daily affairs management, political and ideological education and night shift duty. Students' daily affairs management and night shift duty can be quantified through work projects, but the political and ideological education work needs long time input to achieve effectiveness, and qualitative treatment is needed. Second, the work of instructors is not refined, so it is difficult to reflect the value of individual contribution to work. According to the work content of instructors, it can be divided into three categories: Ideological and political work instructors, students' daily affairs management instructors and graduates' career guidance instructors. The evaluation of ideological and political work instructors should include: Understand the 
thinking of students, the practical performance of students, students' psychological health status, class construction and party development etc. The evaluation of students' daily affairs management instructors should include: Student reward, loan, and other affairs management, student daily life management, issued a leave procedure and all kinds of proof and so on. The evaluation of graduates' career guidance instructors should include: Students career planning, employment guidance, employment statistics planning and so on. Establish different levels of instructor team, to help instructors clear their own position find a way to develop, will be able to play a higher role of instructors.

\section{SUMMARY}

Instructors are the foundation of healthy and rapid development of colleges. However, due to the characteristics of instructors' work, instructors have been in a state of emotional stress and insomnia for a long time. Instructors' ability reserve can't meet the professional requirements of instructors, which makes instructors' sense of occupational efficacy and job belonging low. Instructors' work content is complex, but there is no corresponding incentive and management mechanism, which makes it difficult for instructors to find self-confidence and identity from work. Based on the above reasons, instructors' professional identity is low.
It suggests to enhance the professional identity of college instructors by providing professional training and further study opportunities for instructors, and providing planned characteristic training for instructors, Setting up special career planning and emotion management course for college instructors, improving the evaluation system.

\section{REFERENCES}

[1] LZ. Wang, "research status of professional identity of college instructors", Journal of Shanxi Coal-Mining Administrators College. Vol. 26, pp. 149-150, 2013 ( In Chinese)

[2] YC. Zheng, "qualitative research on professional identity and path choice of college instructors," Ideological Theoretical Education. Vol. 11, pp. 106-110, 2016. ( In Chinese)

[3] HH. Liao, "relationship between emotion regulation ability and professional identity of college instructors ", Science \& Technology Vision. Vol. 4, pp. 111, 2017 ( In Chinese)

[4] YJ. Tao, "research on the adjustment of college instructors' professional identity from the perspective of teacher development", Education Exploration. Vol. 9, PP. 96-98, 2014( In Chinese )

[5] HB. Xu, J. Luo, "three dimensional analysis and construction of college instructors' professional happiness”, Education \& Career. Vol. 33 pp. 83-85, 2014 ( In Chinese)

[6] JD. Zhang, "development status and evaluation countermeasures of college instructors ", Theory and Practice of Education. Vol. 34 pp. 4243, 2014 ( In Chinese) 